\title{
Adolescents amid the COVID-19 pandemic: a prospective study of psychological functioning
}

leva Daniunaite ${ }^{\text {*}^{*}} \mathbb{0}$, Inga Truskauskaite-Kuneviciene ${ }^{1}$, Siri Thoresen², Paulina Zelviene ${ }^{1}$ and Evaldas Kazlauskas ${ }^{1}$

\begin{abstract}
Background: The spread of coronavirus disease (COVID-19) and the accompanying countermeasures can significantly impact the wellbeing of adolescents. There is a lack of longitudinal studies that can shed light on potential social, emotional, and behavioral development in adolescents. We aimed to identify potential changes in adolescent psychosocial functioning from pre-pandemic to peri-pandemic assessment, and secondly, to identify specific patterns of change.

Methods: This longitudinal study was based on a Lithuanian community sample of 331 adolescents aged 12-16 at $\mathrm{T} 1(M=13.87, \mathrm{SD}=1.59)$. T1 data collected before the pandemic (March-June, 2019) was compared with T2 data collected during the COVID-19 outbreak (October 2020). Psychosocial functioning was assessed by The Strengths and Difficulties Questionnaire (SDQ). Multivariate latent change modeling and latent class change approaches were used to identify patterns of change.
\end{abstract}

Results: We found a small but significant increase in hyperactivity/inattention, emotional symptoms, but also prosocial behavior from before to during the pandemic, even adjusting for resilience, lifetime abuse experience, and socio-demographic situation. Three change profiles were identified in the latent change analysis: (1) a majority (70.7\%) experienced a significant increase in psychosocial problems; (2) a smaller sub-group (19.6\%) with increased peer problems only; (3) a small group (9.7\%) showing no negative change and an increase in prosocial behavior.

Conclusions: The study found a significant negative impact of the COVID-19 pandemic on mental health in the majority of adolescents, as well as indications of positive social development in a small group. These findings highlight the importance of identifying and supporting adolescents in the time of the pandemic more effectively. Accumulating knowledge about human responses to the coronavirus, particularly in young people, is pivotal to societal preparedness for future pandemics.

Keywords: COVID-19, Adolescents, Psychosocial functioning, Lithuania

\section{Introduction}

Pandemic diseases may cause major societal disruption and pose great challenges to human adaptation. In recent decades, the likelihood of pandemics has likely increased

\footnotetext{
${ }^{*}$ Correspondence: ieva.daniunaite@fsf.vu.It

${ }^{1}$ Center for Psychotraumatology, Institute of Psychology, Vilnius University, Ciurlionio 29, 01300 Vilnius, Lithuania

Full list of author information is available at the end of the article
}

due to more mobility, urbanization, and other factors [1]. The spread of coronavirus disease (COVID-19) and the accompanying countermeasures can significantly impact the wellbeing of adolescents. Some groups of adolescents might be at a greater risk for serious mental health problems. Previous psychological burden, abuse history, living in a family with low income or low education, belonging to an ethnic minority group are important risk factors for the wellbeing of adolescents during the pandemic [2-6].

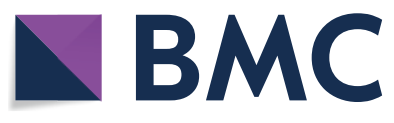

(c) The Author(s) 2021. Open Access This article is licensed under a Creative Commons Attribution 4.0 International License, which permits use, sharing, adaptation, distribution and reproduction in any medium or format, as long as you give appropriate credit to the original author(s) and the source, provide a link to the Creative Commons licence, and indicate if changes were made. The images or other third party material in this article are included in the article's Creative Commons licence, unless indicated otherwise in a credit line to the material. If material is not included in the article's Creative Commons licence and your intended use is not permitted by statutory regulation or exceeds the permitted use, you will need to obtain permission directly from the copyright holder. To view a copy of this licence, visit http://creativecommons.org/licenses/by/4.0/. The Creative Commons Public Domain Dedication waiver (http://creativeco mmons.org/publicdomain/zero/1.0/) applies to the data made available in this article, unless otherwise stated in a credit line to the data. 
In addition, restricted means to psychosocial and social assistance can impact psychosocial functioning $[3,4]$.

Previous studies showed that adolescents worry about the COVID-19 crisis and are very concerned about their schooling restrictions and peer relationships $[7,8]$. Additionally, adolescents reported the negative impact of the COVID-19 pandemic on mental health, learning, friendships, and family relations [6]. Stress, related to the COVID-19 spread and social distancing, was found to be associated with loneliness and depression $[7,9,10]$. Recent studies showed a high level of depression and anxiety in adolescents in different pandemic periods [9, 11-15]. The COVID-19 diagnosis or close contact with an infected person, low social support, and negative coping has been found to relate to higher levels of depression and anxiety $[14,16]$. Furthermore, the COVID-19 pandemic seems to have resulted in higher levels of concentration difficulties and restlessness in children and adolescents, as reported by parents [10].

The vast majority of these studies so far have been cross-sectional. A few longitudinal studies show an increase in depression and anxiety symptoms, also the decrease of mental well-being and lower health-related quality of life from before to during the pandemic [8, 17-20]. The highest level of depression and anxiety were associated with peak infection rates, and the decrease of symptoms paralleled the decline in rates of coronavirus [21]. A recent study showed that adolescent mental health trajectories had been altered in the face of COVID-19 [19]. However, not all studies indicate negative changes in mental health in young people due to the pandemic [22]. Thus, we have a very limited understanding of stability and change in adolescent mental health in the context of the COVID-19 pandemic.

The current study aimed to achieve a better understanding of how the COVID-19 pandemic may have affected adolescent mental health and psychosocial functioning in Lithuania. Previous longitudinal research has demonstrated that in terms of adolescent development, Lithuanians are similar to adolescents from other WEIRD (Western, educated, industrialized, rich, and democratic) countries [23]. The COVID-19-related lockdown in the country resulted in closing schools and distant learning, with school lessons being held online for most of the year 2020. Therefore, the contact with teachers and peers was limited to online communication. Additionally, most parents were working from home. This situation introduced new routines when parents and their children spent extensive time at home while also being busy with their tasks. On the one hand, the adolescents experienced a lack of support from other significant adults and peers. On the other hand, handling the study process became one of the additional burdens for parents. These changes might have introduced exposure to new underexplored communication obligations to both parents and their adolescent children. Regarding the lockdown restrictions, the situation in Lithuania in 2020 was similar to other European countries. We assume that due to rapid changes, stress levels have risen and could have affected adolescents' mental health. Therefore, we first tested if emotional problems, hyperactivity/inattention, behavior problems, and peer problems were higher at 6-months since the first national lockdown during, as compared to before the pandemic. Based on the findings of the previous studies, we hypothesized that adolescent difficulties in emotional and behavioral functioning, problems with peers, and hyperactivity/inattention would be higher than before the pandemic. Second, we sought to identify specific patterns of change. There is substantial evidence that child abuse significantly affects children's and adolescents' psychosocial functioning [24-28]. Also, many studies confirmed that psychological resilience mitigates the negative child abuse effect on psychosocial functioning [24, 29-34]. Therefore, we controlled for child abuse experience and psychological resilience in our latent class change analysis in this study.

\section{Method}

\section{Participants and procedure}

This study is based on the data from the first two waves of the ongoing longitudinal study Stress and Resilience in Adolescence (STAR-A). The STAR-A study is implemented by the Center of Psychotraumatology at Vilnius University in Lithuania. The study was approved by the Ethics Committee for Psychological Research in Vilnius University. Information on the procedures of the STAR-A study has been published previously $[28,35]$.

The current analysis focused on a subsample of 331 adolescents aged 12-16 at the time of the first wave of research, March-May 2019. Data were obtained at two time points: baseline/pre-test (T1, wave 1) and in 18 months at 6 months since the first national lockdown in Lithuania amid the COVID-19 outbreak (T2, wave 2). The T2 data was collected from September 24 to October 21,2020 . During this period, school closing was required at some level [36]. Depending on the COVID-19 situation in the municipality or community, each school could choose the teaching strategy-live, distant, or hybrid. People from outside were not allowed to enter the school premises. Gatherings were restricted to 10 and fewer people [36]. By the start of the data collection on September 24, 2020, there were 9586 identified COVID-19 cases in Lithuania in total, including 116 deaths with a trend of increasing cases and deaths until the end of 2020 [37].

The data for this study were collected in 7 general schools from different regions across Lithuania. Data 
in the first wave was collected using the paper-pencil method. Data in the second wave was collected online through the platform designed for online surveys. The procedures for the $\mathrm{T} 2$ data collection were adapted to the pandemic situation (the second wave of the COVID-19) and valid restrictions in the country. According to the previous adolescent studies, web-based surveys can be applied without the risk of disadvantages compared to paper-pencil assessments [38].

Before starting data collection in 2019, written assent from adolescents and written informed consent from legal guardians were obtained. The protection of study participants' identities was ensured; randomly generated IDs were assigned for the participants in T1. Information about psychological help possibilities was provided to all study participants in $\mathrm{T} 1$ and $\mathrm{T} 2$.

In cooperation with schools, 449 students were invited to participate in T2. Most of the adolescents (336, $74.8 \%$ ) completed the self-report online questionnaire. Responses from five adolescents had to be removed from the analysis because their T1 and T2 data could not be merged due to the lack of identification information provided by the study participant. The final study sample comprised of 331 adolescents, mean age at T1 13.87 $(S D=1.59)$ years, $57.4 \%$ girls $(n=190)$. The majority of participants were born in Lithuania $(98.8 \%, n=327)$ and were of Lithuanian nationality $92.1 \%(n=305)$. More than two-thirds of the sample $(71.3 \%, n=236)$ were from two-parent families. In terms of demographic characteristics, our study sample was not representative but highly comparable with the general population of adolescents [39]. All demographic characteristics of study participants in $\mathrm{T} 2$ are presented in Table 1.

\section{Measures}

\section{Psychosocial functioning}

Psychosocial functioning of adolescents was measured in $\mathrm{T} 1$ and T2 using the Strengths and Difficulties Questionnaire (SDQ) [40]. The SDQ includes 25 items, comprising five scales with five items in each. The response format is a 3-point Likert scale. Five psychosocial functioning dimensions are evaluated: emotional symptoms, conduct problems, hyperactivity, peer problems, and prosocial behavior. The SDQ has been previously validated in Lithuania $[41,42]$. The SDQ is widely used globally and has shown acceptable reliability and validity across many cultures [43].

\section{Resilience}

The psychological resilience of adolescents at T1 was measured by The Resilience Scale (RS-14) [44]. The RS-14 scale includes 14 items measuring the construct of psychological resilience. The response format is a 7-point
Table 1 Characteristics of study participants at T1 $(N=331)$

\begin{tabular}{llr}
\hline Variable & $\boldsymbol{n}$ & $\%$ \\
\hline Gender & 141 & 42.6 \\
Male & 190 & 57.4 \\
Female & & \\
Age & $13.87(1.59)$ & \\
Mean (SD) & $12-16$ & \\
Range & & 71.3 \\
Family structure & 236 & 29.7 \\
Two-parent & 95 & 64.9 \\
Other & & 8.2 \\
University education of parents & 215 & 26.9 \\
One/both of parents & 27 & \\
None & 89 & 98.8 \\
Don't know & & 0.2 \\
Place of birth & 327 & \\
Lithuania & 4 & 3.7 \\
Other & & 4.2 \\
Nationality & & \\
Lithuanian & & \\
Other & 12 & \\
Missing & 14 & \\
\hline
\end{tabular}

Likert scale. The Lithuanian version of the scale was used and validated in the adult and adolescent populations previously $[45,46]$.

\section{Lifetime abuse exposure}

Lifetime abuse exposure was measured in $\mathrm{T} 1$ using the questionnaire developed by the Norwegian Center for Violence and Traumatic Stress Studies (NKVTS). The questionnaire included 37 questions covering six types of abuse: neglect at home (6 items), emotional abuse at home (8 items), physical abuse from an adult at home (6 items), online sexual abuse (5 items), sexual abuse from adults (6 items), sexual abuse from peers (6 items). All single items were reported previously [28]. The response format for neglect questions was a 5-point scale ranging from "never" (0) to "very often/always" (4). The participant was considered as exposed to neglect if (s) he responded to any neglect item with "sometimes" (2), "often" (3), or "very often/always" (4). Concerning the items on all other forms of abuse, the participants were asked to respond on a 4-point scale ranging from "never" (0) to "often" (3). The participant was considered as exposed to emotional abuse if (s)he responded to any emotional abuse item with "sometimes" (2) or "often" (3), and physical/sexual abuse-if (s)he responded to any physical/sexual abuse item accordingly with an answer "once" (1), "sometimes" (2) or "often" (3). Finally, the 
participant was considered as exposed to lifetime abuse, if (s)he has experienced one or more types of abuse.

\section{Data analysis}

To examine the changes in the indicators of adolescent psychosocial functioning at the COVID-19 outbreak (T2), in comparison to pre-test (T1), we used the multivariate latent change modeling approach that provides robust estimates of change over time [47]. In latent change models with two measurement points, the intercept represents the adjusted mean level of the measure at $\mathrm{T} 1$, and the slope represents the change from $\mathrm{T} 1$ to $\mathrm{T} 2$. In the current study, we conducted the latent change model of five parallel processes: change in prosocial behavior, hyperactivity/inattention, emotional symptoms, conduct problems, and peer relationship problems. When running the model, we accounted for possible effects of gender, age, the level of resilience at T1, and the lifetime abuse exposure (exposed vs. not exposed measured a T1) on indicators of psychosocial functioning and included them as control variables by regressing on all intercepts and slopes. To have the latent change model identified, first, we fixed the residuals to zero; second, we fixed non-significant effects of control variables to zero one by one until we obtained the final model with the links of at least marginal significance $(p<0.10)$ only. In addition, to identify whether the change processes in indicators of psychosocial functioning were linked with each other and whether the initial levels of prosocial behavior, hyperactivity/inattention, emotional symptoms, conduct problems, and peer relationship problems were associated with the changes, we correlated all intercepts and slopes. The model fit in latent change analysis was evaluated by using the Comparative Fit Index (CFI), the TuckerLewis Index (TLI), and the Root Mean Square Error of Approximation (RMSEA), following the goodness of fit recommendation provided by Kline [48]. Namely, CFI/ TLI values higher than 0.90 indicated an acceptable fit, and values higher than 0.95 represented a very good fit; RMSEA values below 0.08 indicated an acceptable fit, and values less than 0.05 suggested a good fit.

After running the multivariate latent change model, we sought to identify groups of participants with possibly different patterns of change in indicators of psychosocial functioning by using the latent class change approach [49]. We classified the study participants based on the change in all five indicators (i.e., prosocial behavior, hyperactivity/inattention, emotional symptoms, conduct problems, and peer relationship problems) with also including the control variables used in latent change analysis. We used several criteria to decide on the number of latent classes. First, the Akaike Information Criterion (AIC) and Bayesian Information Criterion (BIC) statistics for a solution with $\mathrm{k}$ classes should be lower than for a solution with $k-1$ classes. Second, a statistically significant $p$ value of the parametric bootstrapped likelihood ratio test, which compares improvement in fit between neighboring class solutions after the inclusion of an additional class. Third, Entropy scores above 0.70 with relatively higher values indicative of more accurate classification. When reporting the change in indicators of psychosocial functioning, the bias-corrected effect sizes [50] were reported. The magnitude of the effect expressed in $d$ was interpreted according to Cohen [51], that is, 0.20 $=$ small effect, $0.50=$ medium effect, and $0.80=$ large effect. The analyses were conducted with Mplus 8.2. [52].

\section{Results}

Means and standard deviations of the study variables at $\mathrm{T} 1$ and $\mathrm{T} 2$, and correlations among them, are presented in Table 2. The correlations between values of each five indicators of socioemotional functioning at T1 and T2 were significant and moderate to high (0.46-0.63). Prosocial behavior at $\mathrm{T} 1$ was significantly negatively associated with hyperactivity/inattention, conduct, and peer problems at T1. Prosocial behavior at T2 was significantly and negatively associated with concurrent hyperactivity/inattention and conduct problems, but significantly and positively with concurrent emotional difficulties.

\section{Change in mental health indicators}

The multivariate latent change analysis yielded an excellent model fit $\left[\mathrm{X}^{2}(26)=26.95, p=0.412\right.$, CFI/TLI $=$ $0.999 / 0.997$, RMSEA $(0 \% \mathrm{CI})=0.010(0.000,0.045)$, $\mathrm{SRMR}=0.029]$. Overall, we found a significant but small increase in rates of hyperactivity/inattention $\left(M_{\text {slope }}=\right.$ $0.45, p<0.001)$ and emotional symptoms $\left(M_{\text {slope }}=0.41\right.$, $p<0.001)$, as well as large increase in prosocial behavior $\left(M_{\text {slope }}=1.32, p=0.034\right)$ from T1 to T2 with no change in conduct problems $\left(M_{\text {slope }}=-0.02, p=0.852\right)$, and peer relationship problems $\left(M_{\text {slope }}=0.07, p=0.495\right)$. For all indicators of psychosocial functioning, we found significant negative links $(p<0.001)$ between intercepts and slopes, indicating that lower baseline rates of prosocial behavior $(r=-0.39)$, hyperactivity/inattention $(r=-0.41)$, emotional symptoms $(r=-0.39)$, conduct problems $(r=-0.48)$, and peer relationship problems $(r=-0.52)$ were associated with bigger increase in these indicators. The trajectories of change in the indicators of psychosocial functioning in a full study sample are presented in Fig. 1.

We found significant gender effects on intercepts of prosocial behavior $\left(\beta_{\text {intercept }}=-0.31, p<0.001\right)$ and emotional symptoms $\left(\beta_{\text {intercept }}=-0.25, p<0.001\right)$, indicating higher baseline rates of these indicators in girls, compared to boys. Also, the results showed 


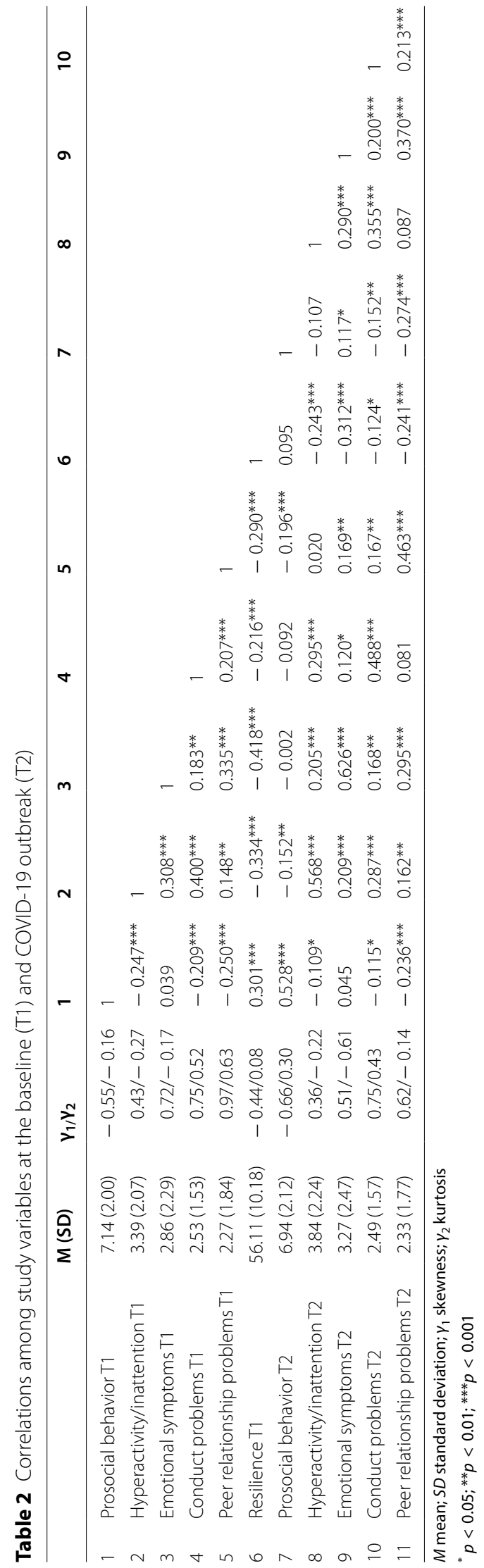



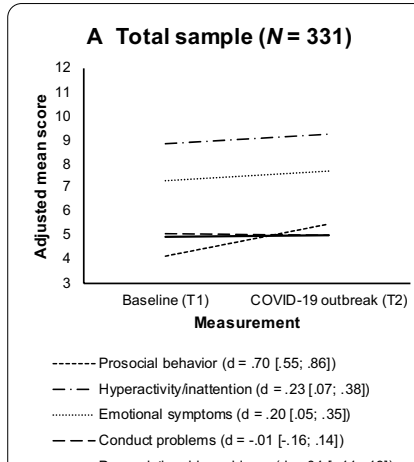
--- Conduct problems $(d=-.01[-.16 ; .14])$ - Peer relationship problems $(d=.04[-.11 ; .19])$
B Strained $(n=234)$

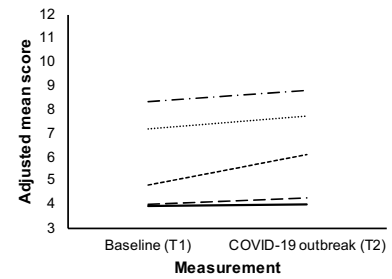

-.-.-.-Prosocial behavior $(\mathrm{d}=.70[.51 ; .89])$

- . - Hyperactivity/inattention $(\mathrm{d}=.24[.06 ; .42])$

............ Emotional symptoms $(\mathrm{d}=.26[.08 ; .44])$

- - - Conduct problems $(d=.19[.01 ; 37])$
C Peer-problems $(n=65)$

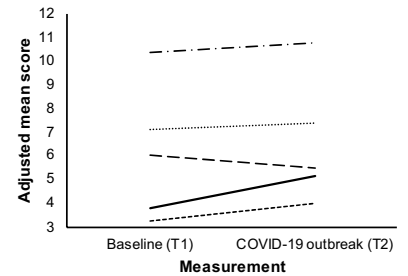

-.-.-.-Prosocial behavior ( $d=44[$ [.09; 799)

- - - Hyperactivityfinattention $(d=.22[-12 ; .57])$

……. Emotional symptoms $(\mathrm{d}=.14[-21 ; .48])$ - - - Conduct problems (d $=-.42[-.77 ;-087)$

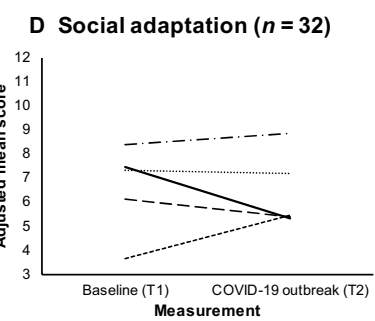

-.-.-. Prosocial behavior $(d=.99[.47 ; 1.51])$ - - Hyperactivity/inattention $(\mathrm{d}=.23[-26 ; .73])$ -......... Emotional symptoms $(\mathrm{d}=-.08[-.57 ; .41])$ - - - Conduct problems ( $d=-.59[-1.09 ;-.09])$ Peer relationship problems $(\mathrm{d}=-1.42[-1.97 ;-.87])$

Fig. 1 The trajectories of change in psychosocial functioning indicators in $\mathbf{A}$ total sample, $\mathbf{B}$ strained, $\mathbf{C}$ peer-problems, and $\mathbf{D}$ social adaptation latent change classes $(N=331)$. $d$ effect size with $95 \%$ confidence intervals. A negative score indicates a decrease, a positive score indicates an increase

significant negative age effects on intercepts of hyperactivity/inattention $\left(\beta_{\text {intercept }}=-0.10, p=0.019\right)$ and conduct problems $\left(\beta_{\text {intercept }}=-0.12, p=0.011\right)$, indicating the higher rates of these indicators at the baseline being associated with younger age. A higher resilience level at T1 was found to be positively linked with the intercept of prosocial behavior $\left(\beta_{\text {intercept }}=\right.$ $0.32, p<0.001)$ and negatively linked to the intercepts of hyperactivity/inattention $\left(\beta_{\text {intercept }}=-0.31\right.$, $p<0.001)$, emotional symptoms $\left(\beta_{\text {intercept }}=-0.35\right.$, $p<0.001)$, conduct problems $\left(\beta_{\text {intercept }}=-0.15, p=\right.$ 0.002), indicating that higher resilience was associated with better psychosocial functioning at baseline. Also, we found significant abuse exposure effects on intercepts of emotional symptoms $\left(\beta_{\text {intercept }}=0.12\right.$, $p=0.002)$, indicating higher levels of internalizing problems at the baseline in the abuse exposure group, compared to the non-exposure group. Finally, we found that the slope of prosocial behavior was significantly negatively linked with resilience $\left(\beta_{\text {intercept }}=-0.18\right.$, $p<0.001)$ and positively linked with abuse exposure $\left(\beta_{\text {intercept }}=0.09, p=0.045\right)$, indicating that the bigger increase in prosocial behavior was observed in adolescents with lower baseline rates of resilience as well as in the abuse exposure group, compared to the non-exposure group.

\section{Patterns of change in psychosocial functioning}

The latent class change analysis indicated that the three classes solution fitted the data best (see Table 3). Three identified change profiles were found to be clearly distinguishable in terms of differences in changes of psychosocial functioning indicator means over time. Most adolescents (70.7\%) reported a significant but small increase in hyperactivity/inattention $\left(M_{\text {slope }}=0.45, p=\right.$ $0.005)$, emotional symptoms $\left(M_{\text {slope }}=0.53, p<0.001\right)$, and conduct problems $\left(M_{\text {slope }}=0.26, p=0.040\right)$ with a stability in prosocial behavior $\left(M_{\text {slope }}=1.26\right.$, $p=0.051)$ and peer relationship problems $\left(M_{\text {slope }}\right.$ $=0.04, p=0.754)$; we labeled this pattern as strained. Almost one in five adolescents (19.6\%) reported large increase in Peer relationship problems $\left(M_{\text {slope }}=1.36, p\right.$ $<0.001)$ with no significant change in other indicators of psychosocial functioning: prosocial behavior $\left(M_{\text {slope }}\right.$ $=0.78, p=0.259)$; hyperactivity/inattention $\left(M_{\text {slope }}\right.$ $=0.43, p=0.369)$, emotional symptoms $\left(M_{\text {slope }}=0.29\right.$, $p=0.411)$, and conduct problems $\left(M_{\text {slope }}=-0.56\right.$, $p=0.085)$; we labeled this pattern as peer-problems.

Table 3 Model fit indices of latent class change analyses

\begin{tabular}{|c|c|c|c|c|c|c|}
\hline Solution & Loglikelihood & AIC & $\mathrm{BIC}$ & Entropy & BLRT $p$-value & $\begin{array}{l}\text { Smallest } \\
\text { class count } \\
(\%)\end{array}$ \\
\hline 1 class & -6333.05 & $12,824.10$ & $13,124.47$ & - & - & - \\
\hline 2 classes & -6333.05 & $12,846.10$ & $13,188.29$ & $<0.001$ & 1.000 & 50.00 \\
\hline 3 classes & -6275.53 & $12,753.07$ & $13,137.08$ & 0.859 & 0.000 & 9.67 \\
\hline 4 classes & -6260.74 & $12,745.48$ & $13,171.32$ & 0.811 & 0.030 & 11.78 \\
\hline
\end{tabular}

The best fitting solution is in bold

AIC Akaike Information Criterion; BIC Bayesian Information Criterion; BLRT Parametric Bootstrapped Likelihood Ratio 
Finally, almost one in ten adolescents (9.7\%) reported a large increase in prosocial behavior $\left(M_{\text {slope }}=1.81\right.$, $p=0.014$ ) and a large decrease in peer relationship problems $\left(M_{\text {slope }}=-12.19, p<0.001\right)$ with a stability in hyperactivity/inattention $\left(M_{\text {slope }}=0.45, p=0.356\right)$, emotional symptoms $\left(M_{\text {slope }}=-0.16, p=0.741\right)$, and conduct problems $\left(M_{\text {slope }}=-0.79, p=0.059\right)$; we labeled this pattern as social adaptation. The trajectories of change in the indicators of psychosocial functioning in three classes are presented in Fig. 1B, C, D. The peerproblems group was characterized by high scores on hyperactivity at both time points. The social adaptation group was characterized by high scores on peer problems at T1.

\section{Discussion}

In this two-wave longitudinal study, we investigated the changes in adolescents' psychosocial functioning amid the COVID-19 pandemic in contrast to pre-pandemic functioning, exploring mental health changes at 6-month since the onset of the first lockdown. In Lithuania, the COVID-19 countermeasures included the closure of schools and restrictions on other essential areas of social life for adolescents in the country. At T2, the schools were just partly reopened. Overall, we found a small but significant increase in hyperactivity/inattention, emotional symptoms, and prosocial behavior. At the same time, the rates of conduct problems and peer problems did not change significantly in the total sample. Our findings align with the results of several previous longitudinal studies, which found higher levels of depression and anxiety among adolescents amid the pandemic $[2,6,8,17$, $18,20]$. However, not all previous studies indicated the negative changes in adolescents' mental health related to the pandemic [22]. In line with the previous studies [5355], emotional problems and prosocial behavior at the baseline were higher in girls than boys. As lower baseline rates of emotional problems were associated with a bigger increase, boys may have suffered a bigger increase in emotional problems amid the pandemic. Overall, our results highlight that adolescents in the general population experience psychosocial difficulties during the pandemic, which might constitute a risk for future mental health problems.

Analysis of specific patterns of change in adolescents' psychosocial functioning revealed three different change profiles of adolescents' psychosocial functioning compared to before the pandemic. This analysis gives us insights into specific challenges different groups of adolescents can meet during this or future pandemics. Based on this analysis, scientists and practitioners can plan different specific prevention and intervention strategies. Around two-thirds of the sample had a small but significant increase in hyperactivity/inattention, emotional symptoms, and conduct problems (strained group). These changes can be related to pandemic stress and life changes, loneliness, social isolation, distant learningrelated concentration difficulties, or lack of motivation $[5,9,10,12,56]$. General prevention strategies, helping to organize the learning environment and daily tasks, emotional support and stress management strategies, can be helpful for the majority of adolescents and young people. These could include the online adaptation of prevention and socio-emotional skills training programs, discussions, groups activities, and social gatherings online.

According to our results, one in five adolescents experienced an increased peer problems (peer-problems group) compared to before the pandemic. The previous studies show that increased peer problems can be associated with social restrictions, social isolation, less time with friends, and less perceived friend support [9, 17]. The analysis showed that this subgroup had a high level of hyperactivity or attention problems before the pandemic. Adolescents with hyperactivity and attention problems can have more difficulties adapting to the changing conditions and keeping social contacts online. Peer relationship and hyperactivity/inattention problems are serious risk factors for later mental health disorders $[2,57]$. The results indicate that parents, teachers, and other school personnel should pay particular attention to the social relationships in this group and foster positive ways of online communication. The previous studies show that the core elements of adolescent friendships persist in online communication [58]. Further research is, however, necessary to replicate this finding in other contexts and samples.

Finally, our study shows that almost one in ten adolescents reported a significant decrease in peer relationship problems and an increase in prosocial behavior (social adaptation group) with the stability in other indicators compared to before the pandemic. This group of adolescents, who experienced a relatively high level of peer problems before the pandemic, showed a substantial decrease in peer problems during the pandemic. An increase of prosocial behavior in the COVID-19 pandemic context and after other stressful events was already documented in the previous studies and can be recognized as a positive adaptation $[59,60]$. Reduction of peer problems might be associated with the previous difficulties with peers in school, such as bullying. We speculate that these adolescents might have difficulties when they return to school, and need to be recognized and supported by professionals. The results show that such stressful situations as pandemics and lockdown can release prosocial communication opportunities for some adolescents. School staff can use these findings by 
promoting volunteering and positive interactions in creative ways.

The changes in adolescents' psychosocial functioning can be associated with the circumstances related to the pandemics-school closures, restrictions on after-school activities, social contacts with relatives and friends. The study results provide insights for prevention and intervention strategies for the pandemic and post-pandemic period, also preparation for possible future disasters and stressors. General prevention strategies for psychosocial difficulties and specific strategies helping adolescents creating safe contacts and maintain friendships are needed in such periods as lockdowns and school closures. Still, some adolescents can be struggling more with daily communication with peers when they come back to direct learning. Future longitudinal research to follow the trajectories of adolescents' functioning after the pandemic is needed.

\section{Limitations}

The current study has many strengths, including the longitudinal design, high response rate, and inclusion of the pre-pandemic measures to estimate changes in psychosocial functioning during the COVID-19 pandemic. Still, several limitations are to be mentioned. Despite the longitudinal data collection on psychosocial functioning, it is not possible to attribute the detected changes specifically to the effects of the COVID-19 pandemic on mental health. The time between the two measures of 18 months is a relatively long period in an adolescent's life, and many changes in family and peer life can happen during such time. Moreover, the data were based on self-report and more objective assessments of psychosocial functioning, and reports from parents and teachers could address this limitation in future studies. Finally, the data were collected in one European country with a relatively homogenous sample in a high-income country. It cannot be ensured that the results are generalizable to all the countries, especially having different COVID-19 rates and variable government response measures across countries, more heterogeneous, and migrant populations.

\section{Conclusions}

This study contributes to the existing literature by showing a decline in the psychosocial functioning of adolescents as a potential consequence of the pandemic. Our findings highlight the importance of prevention and intervention measures to help adolescents cope with psychosocial challenges related to pandemics or similar highly stressful situations in the future. Changes in psychosocial functioning can serve as an antecedent of later mental health problems. Peer relations in the context of social restrictions and after returning to school require special attention, and fostering the adolescents' prosocial behavior can act as an important protective factor. Moreover, parents and professionals should be capable of monitoring the psychosocial functioning of adolescents and provide the needed support, according to the specific challenges adolescents meet. Prevention measures of mental health problems in adolescence, responding to the pandemic-related challenges, and returning to usual daily life routine challenges, are needed.

\section{Abbreviations \\ COVID-19: Coronavirus disease of 2019; SDQ: The Strengths and Difficulties Questionnaire; RS-14: The Resilience Scale; CFI: Comparative Fit Index; TLI: The Tucker-Lewis Index; RMSEA: The Root Mean Square Error of Approximation.}

\section{Acknowledgements}

We thank all the adolescents who participated in the study and all the schools that helped organize fluent data collection.

\section{Authors' contributions}

ID: writing —original draft; ID, ITK, ST, PZ, EK: writing — review and editing; ID, PZ: data collection; ITK: data analysis; EK, PZ: principal investigators; ST, EK: supervision. All authors read and approved the final manuscript.

\section{Funding}

No Funding to report for this study.

\section{Availability of data and materials}

The datasets generated and analyzed during the current study are not publicly available due to ethical reasons but are available from the corresponding author on reasonable request.

\section{Declarations}

\section{Ethics approval and consent to participate}

Ethics approval was issued by the Ethics Committee for Psychological Research in Vilnius University (2019-03-06, No. 23). Before the data collection, all the adolescents participating in the study and their parents signed the written form of consent. Informed consent was obtained from all individual participants. The adolescents of non-consenting parents did not participate in the study.

\section{Consent for publication}

NA.

\section{Competing interests}

The authors declare that they have no competing interests.

\section{Author details}

${ }^{1}$ Center for Psychotraumatology, Institute of Psychology, Vilnius University, Ciurlionio 29, 01300 Vilnius, Lithuania. ${ }^{2}$ Norwegian Center for Violence and Traumatic Stress Studies, Oslo, Norway.

Received: 14 May 2021 Accepted: 12 August 2021

Published online: 31 August 2021

\section{References}

1. Verguet S, Jamison DT. Health policy analysis: applications of extended cost-effectiveness analysis methodology in disease control priorities, third edition. In: Disease control priorities: improving health and reducing poverty, vol. 9. 3rd ed. Bethesda: U.S. National Library of Medicine; 2017. p. 157-66.

2. Breaux R, Dvorsky MR, Marsh NP, Green CD, Cash AR, Shroff DM, et al. Prospective impact of COVID-19 on mental health functioning in 
adolescents with and without ADHD: protective role of emotion regulation abilities. J Child Psychol Psychiatry Allied Discip. 2021. https://doi. org/10.1111/jcpp.13382.

3. Fegert JM, Vitiello B, Plener PL, Clemens V. Challenges and burden of the Coronavirus 2019 (COVID-19) pandemic for child and adolescent mental health: a narrative review to highlight clinical and research needs in the acute phase and the long return to normality. Child Adolesc Psychiatry Ment Health. 2020;14(1):1-11. https://doi.org/10.1186/ s13034-020-00329-3.

4. Singh S, Roy D, Sinha K, Parveen S, Sharma G, Joshi G. Impact of COVID-19 and lockdown on mental health of children and adolescents: A narrative review with recommendations. Psychiatry Res. 2020;293: 113429. https:// doi.org/10.1016/.jpsychres.2020.113429.

5. Sibley MH, Ortiz M, Gaias LM, Reyes R, Joshi M, Alexander D, et al. Top problems of adolescents and young adults with ADHD during the COVID-19 pandemic. J Psychiatr Res. 2021;136:190-7. https://doi.org/10. 1016/j.jpsychires.2021.02.009.

6. Li SH, Beames JR, Newby JM, Maston K, Christensen H, Werner-Seidler A. The impact of COVID-19 on the lives and mental health of Australian adolescents. Eur Child Adolesc Psychiatry. 2021. https://doi.org/10.1007/ s00787-021-01790-X.

7. Ellis WE, Dumas TM, Forbes LM. Physically isolated but socially connected: psychological adjustment and stress among adolescents during the initial COVID-19 crisis. Can J Behav Sci. 2020;52(3):177-87. https://doi.org/ $10.1037 / \mathrm{cbs} 0000215$.

8. Magson NR, Freeman JYA, Rapee RM, Richardson CE, Oar EL, Fardouly J. Risk and protective factors for prospective changes in adolescent mental health during the COVID-19 pandemic. J Youth Adolesc. 2021;50(1):4457. https://doi.org/10.1007/s10964-020-01332-9.

9. Loades ME, Chatburn E, Higson-Sweeney N, Reynolds S, Shafran R, Brigden A, et al. Rapid systematic review: the impact of social isolation and loneliness on the mental health of children and adolescents in the context of COVID-19. J Am Acad Child Adolesc Psychiatry. 2020;59(11):1218-1239. e3. https://doi.org/10.1016/j.jaac.2020.05.009.

10. Orgilés M, Morales A, Delvecchio E, Mazzeschi C, Espada JP. Immediate psychological effects of the COVID-19 quarantine in youth from Italy and Spain. Front Psychol. 2020;1 ( (November):1-10. https://doi.org/10.3389/ fpsyg.2020.579038.

11. Li W, Zhang Y, Wang J, Ozaki A, Wang Q, Chen Y, et al. Association of Home Quarantine and Mental Health among Teenagers in Wuhan, China, during the COVID-19 Pandemic. JAMA Pediatr. 2021. https://doi.org/10.1001/ jamapediatrics.2020.5499.

12. de Miranda MD, da Silva Athanasio B, Sena Oliveira AC, Simoes-E-Silva AC. How is COVID-19 pandemic impacting mental health of children and adolescents? Int J disaster risk Reduct IJDRR. 2020;51:101845 (32929399). https://doi.org/10.1016/j.ijdrr.2020.101845.

13. McGuine TA, Biese KM, Petrovska L, Hetzel SJ, Reardon C, Kliethermes S, et al. Mental health, physical activity, and quality of life of US adolescent athletes during COVID-19-related school closures and sport cancellations: a study of 13000 athletes. J Athl Train. 2021;56(1):11-9. https://doi. org/10.4085/1062-6050-0478.20

14. Qi M, Zhou SJ, Guo ZC, Zhang LG, Min HJ, Li XM, et al. The effect of social support on mental health in chinese adolescents during the outbreak of COVID-19. J Adolesc Heal. 2020;67(4):514-8. https://doi.org/10.1016/j. jadohealth.2020.07.001

15. Zhou SJ, Zhang LG, Wang LL, Guo ZC, Wang JQ, Chen JC, et al. Prevalence and socio-demographic correlates of psychological health problems in Chinese adolescents during the outbreak of COVID-19. Eur Child Adolesc Psychiatry. 2020;29(6):749-58. https://doi.org/10.1007/ s00787-020-01541-4.

16. Zhang C, Ye M, Fu Y, Yang M, Luo F, Yuan J, et al. The psychological impact of the COVID-19 pandemic on teenagers in China. J Adolesc Heal. 2020;67(6):747-55. https://doi.org/10.1016/j.jadohealth.2020.08.026.

17. Rogers AA, Ha T, Ockey S. Adolescents' perceived socio-emotional impact of COVID-19 and implications for mental health: results from a US-based mixed-methods study. J Adolesc Heal. 2021;68(1):43-52. https://doi.org/ 10.1016/j.jadohealth.2020.09.039.

18. Thorisdottir IE, Asgeirsdottir BB, Kristjansson AL, Valdimarsdottir HB, Jonsdottir Tolgyes EM, Sigfusson J, et al. Depressive symptoms, mental wellbeing, and substance use among adolescents before and during the COVID-19 pandemic in Iceland: a longitudinal, population-based study.
Lancet Psychiatry. 2021;0366(21):1-10. https://doi.org/10.1016/S22150366(21)00156-5.

19. De France K, Hancock GR, Stack DM, Serbin LA, Hollenstein T. The mental health implications of COVID-19 for adolescents: follow-up of a four-wave longitudinal study during the pandemic. Am Psychol. 2021. https://doi. org/10.1037/amp0000838.

20. Ravens-Sieberer U, Kaman A, Erhart M, Devine J, Schlack R, Otto C Impact of the COVID-19 pandemic on quality of life and mental health in children and adolescents in Germany. Eur Child Adolesc Psychiatry. 2021. https://doi.org/10.1007/s00787-021-01726-5.

21. Hawes MT, Szenczy AK, Olino TM, Nelson BD, Klein DN. Trajectories of depression, anxiety and pandemic experiences; a longitudinal study of youth in New York during the Spring-Summer of 2020. Psychiatry Res. 2021;298: 113778. https://doi.org/10.1016/j.psychres.2021.113778.

22. Hafstad GS, Sætren SS, Wentzel-Larsen T, Augusti E-M. Adolescents' symptoms of anxiety and depression before and during the COVID19 outbreak - a prospective population-based study of teenagers in Norway. Lancet Reg Heal Eur. 2021;5:100093. https://doi.org/10.1016/j. lanepe.2021.100093.

23. Žukauskienè R, Truskauskaitè-Kunevičienè I, Kaniušonytè G, Crocetti E. How do Lithuanian adolescents address identity questions? A four-wave longitudinal study on change and stability in identity styles. Eur J Dev Psychol. 2018;15(1):41-60. https://doi.org/10.1080/17405629.2017.12857 62.

24. Cicchetti D. Annual research review: resilient functioning in maltreated children — past, present, and future perspectives. J Child Psychol Psychiatry Allied Discip. 2013;54(4):402-22. https://doi.org/10.1111/j.1469-7610. 2012.02608.x.

25. Finkelhor D, Ormrod RK, Turner HA. Lifetime assessment of poly-victimization in a national sample of children and youth. Child Abus Negl. 2009:33(7):403-11. https://doi.org/10.1016/..chiabu.2008.09.012.

26. Melville A. Adverse childhood experiences from ages $0-2$ and young adult health: implications for preventive screening and early intervention. J Child Adolesc Trauma. 2017;10(3):207-15. https://doi.org/10.1007/ s40653-017-0161-0.

27. Roberts YH, English D, Thompson R, White CR. The impact of childhood stressful life events on health and behavior in at-risk youth. Child Youth Serv Rev. 2018;85:117-26. https://doi.org/10.1016/j.childyouth.2017.11. 029.

28. Zelviene P, Daniunaite I, Hafstad GS, Thoresen S, Truskauskaite-Kuneviciene I, Kazlauskas E. Patterns of abuse and effects on psychosocial functioning in Lithuanian adolescents: a latent class analysis approach. Child Abus Negl. 2020. https://doi.org/10.1016/j.chiabu.2020.104684.

29. Ding H, Han J, Zhang M, Wang K, Gong J, Yang S. Moderating and mediating effects of resilience between childhood trauma and depressive symptoms in Chinese children. J Affect Disord. 2017;211:130-5. https://doi.org/ 10.1016/j.jad.2016.12.056.

30. Masten AS. Resilience in children threatened by extreme adversity: frameworks for research, practice, and translational synergy. Dev Psychopathol. 2011;23(2):493-506. https://doi.org/10.1017/S0954579411000198.

31. Southwick SM, Bonanno GA, Masten AS, Panter-Brick C, Yehuda R. Resilience definitions, theory, and challenges: interdisciplinary perspectives. Eur J Psychotraumatol. 2014;5:1-14. https://doi.org/10.3402/ejpt.v5. 25338.

32. Nooner KB, Litrownik AJ, Thompson R, Margolis B, English DJ, Knight ED, et al. Youth self-report of physical and sexual abuse: a latent class analysis. Child Abus Negl. 2010;34(3):146-54. https://doi.org/10.1016/j.chiabu. 2008.10.007.

33. Sattler KMP, Font SA. Resilience in young children involved with child protective services. Child Abus Negl. 2018;75:104-14. https://doi.org/10. 1016/j.chiabu.2017.05.004.

34. Segura A, Pereda N, Guilera G, Hamby S. Resilience and psychopathology among victimized youth in residential care. Child Abus Negl. 2017;72:301-11. https://doi.org/10.1016/..chiabu.2017.08.019.

35. Kazlauskas E, Zelviene P, Daniunaite I, Hyland P, Kvedaraite M, Shevlin M, et al. The structure of ICD-11 PTSD and Complex PTSD in adolescents exposed to potentially traumatic experiences. J Affect Disord. 2020. https://doi.org/10.1080/20008198.2017.1414559.

36. OxCGRT. Coronavirus government response tracker. COVID-19 government response tracker. Oxford: Blavatnik School of Government; 2020. 
37. World Health Organization. Coronavirus disease (COVID-19) pandemic; 2021. https://www.who.int/emergencies/diseases/novel-coronavirus2019/situation-reports. Accessed 31 Mar 2021

38. Zeiler M, Peer S, Philipp J, Truttmann S, Wagner G, Karwautz A, et al. Webbased versus paper-pencil assessment of behavioral problems using the youth self-report. Eur J Psychol Assess. 2021. https://doi.org/10.1027/ 1015-5759/a000585.

39. Official Statistics Portal. Children of Lithuania, 2020; 2021. https://osp.stat. gov.lt/lietuvos-vaikai. Access 3 May 2021.

40. Goodman R. The strengths and difficulties questionnaire: a research note. J Child Psychol Psychiatry Allied Discip. 1997;38(5):581-6. https://doi.org/ 10.1111/j.1469-7610.1997.tb01545.x.

41. Gintilienè G, Girdzijauskienè S, Černiauskaitè D, Lesinskienè S, Povilaitis R, Pūras D. A standardised Lithuanian version of Strenghts and Difficulties Questionnaire (SDQ) for school-aged children. Psichologija. 2004;29:88-105.

42. Lesinskiene S, Girdzijauskiene S, Gintiliene G, Butkiene D, Puras D, Goodman $\mathrm{R}$, et al. Epidemiological study of child and adolescent psychiatric disorders in Lithuania. BMC Public Health. 2018;18(1):1-8. https://doi.org/ 10.1186/s12889-018-5436-3.

43. Goodman R. Psychometric properties of the strengths and difficulties questionnaire. J Am Acad Child Adolesc Psychiatry. 2001. https://doi.org/ 10.1097/00004583-200111000-00015.

44. Wagnild G. A review of the resilience Scale. J Nurs Meas. 2009. https://doi. org/10.1891/1061-3749.17.2.105.

45. Mažulytè E, Skerytė-Kazlauskienè M, Eimontas J, Gailienè D, Grigutytè N, Kazlauskas E. Trauma experience, psychologicalresilience and dispositional optimism: three adult generations in Lithuania. Psichologija. 2014;1:49. https://doi.org/10.15388/psichol.2014.49.3696.

46. Zelviene P, Jovarauskaite L, Truskauskaite-Kuneviciene I. The psychometric properties of the resilience scale (RS-14) in Lithuanian adolescents. Front Psychol. 2021;12:1-7. https://doi.org/10.3389/fpsyg.2021.667285.

47. Duncan TE, Duncan SC, Strycker LA. An introduction to latent variable growth curve modeling: concepts, issues, and applications. Mahwah: Lawrence Erlbaum Associates Publishers; 2013. p. 197.

48. Kline RB. Principles and practice of structural equation modeling. 3rd ed. New York: Guilford Press; 2011. p. 427.

49. Jung T, Wickrama KA. An introduction to latent class growth analysis and growth mixture modeling. Soc Personal Psychol Compass. 2008;2(1):30217. https://doi.org/10.1111/j.1751-9004.2007.00054.x.
50. Fritz CO, Morris PE, Richler JJ. Effect size estimates: current use, calculations, and interpretation. J Exp Psychol Gen. 2012;141(1):2-18.

51. Cohen J. Statistical power analysis for the behavioral sciences. 2nd ed. Nillsdale: Lawrence Earlbaum Associates; 1988

52. Muthén LK, Muthén BO. Mplus user's guide. 8th ed. Los Angeles: Muthén \& Muthén; 2017.

53. Van der Graaff J, Carlo G, Crocetti E, Koot HM, Branje S. Prosocial behavior in adolescence: gender differences in development and links with empathy. J Youth Adolesc. 2018;47(5):1086-99. https://doi.org/10.1007/ s10964-017-0786-1.

54. Haugan JA, Frostad P, Mjaavatn PE. Girls suffer: the prevalence and predicting factors of emotional problems among adolescents during upper secondary school in Norway. Soc Psychol Educ. 2021;24(3):609-34. https://doi.org/10.1007/s11218-021-09626-x.

55. Van Droogenbroeck F, Spruyt B, Keppens G. Gender differences in mental health problems among adolescents and the role of social support: results from the Belgian health interview surveys 2008 and 2013. BMC Psychiatry. 2018;18(1):1-9. https://doi.org/10.1186/s12888-018-1591-4.

56. Liu Y, Yue S, Hu X, Zhu J, Wu Z, Wang JL, et al. Associations between feelings/behaviors during COVID-19 pandemic lockdown and depression/ anxiety after lockdown in a sample of Chinese children and adolescents. J Affect Disord. 2021;284:98-103. https://doi.org/10.1016/j.jad.2021.02.001.

57. Orben A, Tomova L, Blakemore SJ. The effects of social deprivation on adolescent development and mental health. Lancet Child Adolesc Health. 2020. https://doi.org/10.1016/S2352-4642(20)30186-3.

58. Yau JC, Reich SM. Are the qualities of adolescents' offline friendships present in digital interactions? Adolesc Res Rev. 2018;3(3):339-55. https:// doi.org/10.1007/s40894-017-0059-y.

59. Larson A, Moses T. Examining the link between stress events and prosocial behavior in adolescents: more ordinary magic? Youth Soc. 2017:49(6):779-804. https://doi.org/10.1177/0044118X14563049.

60. Van de Groep S, Zanolie K, Green KH, Sweijen SW, Crone EA. A daily diary study on adolescents' mood, empathy, and prosocial behavior during the COVID-19 pandemic. PLoS ONE. 2020;15:1-20. https://doi.org/10.1371/ journal.pone.0240349.

\section{Publisher's Note}

Springer Nature remains neutral with regard to jurisdictional claims in published maps and institutional affiliations.
Ready to submit your research? Choose BMC and benefit from:

- fast, convenient online submission

- thorough peer review by experienced researchers in your field

- rapid publication on acceptance

- support for research data, including large and complex data types

- gold Open Access which fosters wider collaboration and increased citations

- maximum visibility for your research: over $100 \mathrm{M}$ website views per year

At BMC, research is always in progress.

Learn more biomedcentral.com/submissions 